\title{
Energy efficiency of batch and semi-batch (CCRO) reverse osmosis
}

\section{desalination}

David M. Warsinger ${ }^{\mathrm{a}, 1}$, Emily W. Tow ${ }^{\mathrm{a}, \mathrm{1}}$, Kishor G. Nayar ${ }^{\mathrm{a}}$, Laith A. Maswadeh ${ }^{\mathrm{b}}$, and John H. Lienhard Va,

a. Rohsenow Kendall Heat Transfer Laboratory, Department of Mechanical Engineering, Massachusetts Institute of Technology, 77 Massachusetts Avenue, Cambridge, MA 02139-4307 USA

b. Department of Management Science and Engineering, Stanford University, 450 Serra Mall, Stanford, CA 98305

$1 \quad$ Authors contributed equally to this work

* Corresponding Author lienhard@mit.edu

ABSTRACT: As reverse osmosis (RO) desalination capacity increases worldwide, the need to reduce its specific energy consumption becomes more urgent. In addition to the incremental changes attainable with improved components such as membranes and pumps, more significant reduction of energy consumption can be achieved through time-varying $\mathrm{RO}$ processes including semi-batch processes such as closed-circuit reverse osmosis (CCRO) and fully-batch processes that have not yet been commercialized or modeled in detail. In this study, numerical models of the energy consumption of batch RO (BRO), CCRO, and the standard continuous RO process are detailed. Two new energy-efficient configurations of batch RO are analyzed. Batch systems use significantly less energy than continuous RO over a wide range of recovery ratios and source water salinities. Relative to continuous RO, models predict that CCRO and batch RO demonstrate up to $37 \%$ and $64 \%$ energy savings, respectively, for brackish water desalination at high water recovery. For batch RO and CCRO, the primary reductions in energy use stem from atmospheric pressure brine discharge and reduced streamwise variation in driving pressure. Fully-batch systems further reduce energy consumption by not mixing streams of 
different concentrations. These results demonstrate that time-varying processes can significantly raise RO energy efficiency.

\section{Keywords}

Desalination, batch reverse osmosis, energy efficiency, pressure recovery, reverse osmosis, closed-circuit reverse osmosis

\section{INTRODUCTION}

More than two-thirds of the world's population face severe water scarcity for at least one month in a year (Mekonnen and Hoekstra, 2016) with water demand outstripping net available precipitation for half the world's population. Rapid population growth and climate change are causing the availability of freshwater resources around the world to vary significantly in both space and time (Kundzewicz et al., 2008, Oki and Kanae, 2006), leading to increased reliance on groundwater withdrawal (Miller, 2003, Pangarkar et al., 2011, Richey et al., 2015) as well as increased demand for producing freshwater from saline sources through desalination, including groundwater desalination, seawater desalination (Warsinger et al., 2014), agricultural water reuse (McCool et al., 2010), and potable water reuse (Yarlagadda et al., 2011). The dominant technology used to meet these demands is reverse osmosis (RO), which is the most efficient technology for most water sources (Thiel et al., 2015, Tow et al., 2015).

Increasing the energy efficiency of $\mathrm{RO}$ is important in making the technology more sustainable. Researchers have typically improved energy efficiency of the conventional RO process by developing better membranes, however the improvement in practical efficiencies in recent years have been fairly incremental. This study examines the efficiency improvements that could be attained by utilizing time-variant RO systems. Numerical modelling is used to compare batch and semi-batch RO processes against conventional RO across a range of 
source water salinities and system recovery ratios to identify regimes of significant energy efficiency

improvement.

\section{BACKGROUND: TIME-VARIANT RO PROCESSES}

\subsection{Closed-circuit reverse osmosis}

Closed-circuit reverse osmosis (CCRO) is a semi-batch process in which feed is continuously added to the system over time. In a CCRO system, feed water is pumped into a pressure vessel outfitted with spiral-wound RO membranes (the "membrane module"). Pure water passes through the membrane while the remaining solution is concentrated. The outgoing concentrate is then recirculated and mixed with feed water that has been pressurized, and this mixture is returned to the membrane module to be further concentrated. The liquid pressure increases over time to overcome the solution osmotic pressure, which increases as the solution is concentrated. Once the desired recovery ratio is reached, brine is ejected and replaced by new feed in preparation for the next cycle. Several designs have been proposed in the patent literature for CCRO (Bratt, 1989, Pelmulder, 1981, Szucz and Szucs, 1991).

While the pressure along the entire flow path of a continuous RO system must be maintained at a value above the maximum osmotic pressure of the brine, the pressure in a CCRO process varies over time with the osmotic pressure of the feed (Stover, 2013a). This allows for significant reductions in energy consumption in CCRO compared to continuous RO. However, the efficiency of the CCRO process is limited by the continuous mixing of brine with the incoming feed solution, which generates entropy (Warsinger et al., 2015).

Past studies of CCRO have modelled the process as a series of steady cycles with step pressure increases in between them (Lin and Elimelech, 2015, Nayar et al., 2015, Stover, 2013b). This is a tolerable approximation for high recoveries (large numbers of cycles) with the cycles generally capturing the performance variation in time. However, these models do not capture the salinity profiles within the module. Furthermore, the discrete nature of the cycles prevents this modelling method from being used to study batch RO systems, which reach high recovery in few cycles. In order to improve the accuracy and make a fair comparison to the batch process, the 
present study models CCRO as a temporally- and spatially-varying process by discretizing the relevant equations.

\subsection{Other batch configurations}

Batch reverse osmosis technologies are configurations that vary their salinity over time by recycling brine (Qiu and Davies, 2012). In this paper, "batch RO” signifies that RO brine is recirculated through the RO membrane module without incorporating any fresh feed. While the idea of a completely batch RO was proposed by Szucz and Szucs (Szucz and Szucs, 1991)) as early as, 1991, the concept was further developed more recently by various inventors. Oklejas proposed systems where the brine recirculation was integrated within the RO pressure vessel (Oklejas Jr, 2014). Systems with variable feed pressure have also been proposed (Oklejas Jr, 2011).

Published studies on the modelling and performance of batch RO systems are limited. Barello conducted experiments on a batch $\mathrm{RO}$ process to study the influence of pressure and feed salinity on the water permeability constant of the membrane (Barello et al., 2015). Liu et al. and others analyze the minimal energy requirements in a general framework, including the modelling of a variable pressure piston (Liu et al., 2011). While this is a batch process, it includes no context of a real RO system or its components, and instead serves to represent batch as the least energy possible for RO. Numerous other papers estimate the least possible energy for reverse osmosis (Greenlee et al., 2009, Lazarova et al., 2012, Semiat, 2008, Tribus and Evans, 1963, Lienhard V et al., 2017), which can be achieved in only in a perfect batch process.

To our knowledge, no detailed model for calculating the energy requirements of complete batch RO systems has been published.

\section{MODELING METHODS}

Energy models are developed for three RO process types (continuous, semi-batch, and batch) to enable comparisons between them. To make the comparisons fair, design parameters such as pump efficiency are kept the same between models. Rather than developing detailed mass transfer models for all three systems, the driving force for water flux (gauge pressure minus osmotic pressure) at the brine outlet is kept constant as a 
proxy for fixing the membrane area. The energy consumption of the three RO process types is then compared across a range of feed salinities and recovery ratios. The MATLAB script used to evaluate the model presented in this section is provided in the supplementary materials.

3.1 System comparisons System comparisons are made at fixed recovery ratio, RR, which is defined as the fraction of feed water recovered as permeate. For a continuous system,

$$
\mathrm{RR}=\frac{\dot{V}_{p}}{\dot{V}_{f}}
$$

and for a batch or semi-batch system,

$$
\mathrm{RR}=\frac{V_{p, \text { cycle }}}{V_{f, \text { cycle }}}
$$

Here, $\dot{V}_{f}$ and $\dot{V}_{p}$ are the volume flow rates of feed and permeate in a continuous RO system, while $V_{f \text {,cycle }}$ and

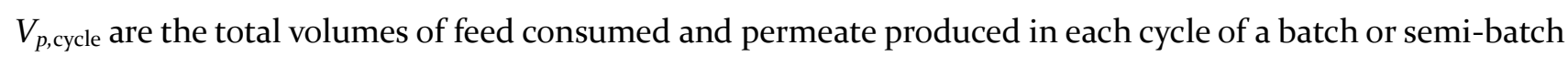
process.

In addition to RR, several other parameters are held constant across all systems considered. The module recovery ratio, $R R_{m}$, which is defined as the fraction of feed extracted as permeate in a single pass through the membrane module, is also fixed. Feed solution composition varies widely between water sources, but for the purpose of this comparison, feeds will be represented by aqueous sodium chloride solutions for all processes. Solution osmotic pressure is calculated at, $20^{\circ} \mathrm{C}$ using the Pitzer model for electrolyte solution properties (see e.g., (Pitzer, 1973)). All pump efficiencies are fixed at 8o \%. Although pretreatment energy consumption can be a significant fraction of the total in low-salinity applications (Chang et al., 2008), it is left out of this analysis because it is expected to be similar for all systems. For the purpose of this energetic comparison, salt permeation is neglected and thus the permeate osmotic pressure is assumed to be zero. Finally, to ensure sufficient flux, all models have the same minimum (terminal) driving pressure difference $\Delta P_{t}$, equal to the difference between gauge pressure and bulk solution osmotic pressure at the brine outlet. 


\subsection{Continuous RO configuration}

Continuous RO is simple to model because it is time-invariant. Figure 1 shows a continuous RO system, which consists of a feed pump and a train of RO modules.

Figure 1. here

Neglecting salt permeation through the membrane, the salinity (as salt mass fraction) can be calculated with Eq. (3) from steady conservation of salt:

$$
s_{b}=\frac{s_{f}}{1-\mathrm{RR}},
$$

where $s_{b}$ and $s_{f}$ are the brine and feed salinities, respectively.

The specific energy consumption $w_{R O}$ of the simple RO system without inter-stage booster pumps or energy recovery is then derived as:

$$
w_{R O}=\frac{\pi_{b}+\Delta P_{t}+N \Delta P_{l}}{\eta_{p} \mathrm{RR}}
$$

where $N$ is the number of stages needed to reach a recovery ratio of RR with a per-module recovery of $\mathrm{RR}_{\mathrm{m}}, \pi_{b}$ is the brine osmotic pressure, $\Delta P_{l}$ is the viscous pressure drop per module, and $\eta_{p}$ is the pump efficiency. In practice, $N$ would be rounded to a whole number, and the module size or applied pressure would be adjusted to achieve the desired recovery ratio. However, for the purpose of this multi-system comparison at constant RR and $R R_{m}$, non-integer numbers of stages (i.e., a smaller final stage) are allowed when computing the viscous pressure drop. The theoretical number of RO stages is calculated from the following equation,

$$
N=\frac{\ln \left(\begin{array}{ll}
1 & \mathrm{RR}
\end{array}\right)}{\ln \left(\begin{array}{ll}
1 & \mathrm{RR}_{m}
\end{array}\right)},
$$


which we derived by noting that the feed volume is reduced by a factor of $1-R_{m}$ in each stage to an eventual volume of 1-RR times the initial volume. For example, an overall recovery of $R R=87.5 \%$ with a stage recovery of $\mathrm{RR}_{\mathrm{m}}=50 \%$ would give $\mathrm{N}=3$ stages.

RO energy consumption can be reduced by incorporating a pressure exchanger with an exergetic efficiency of $\eta_{P X}$ and a post-pressure exchanger booster pump of efficiency $\eta_{b}$ :

$$
\begin{aligned}
& w_{R O+E R D}=\frac{{ }_{b}+P_{t}+N P_{l}}{p} \\
& +\frac{\left({ }_{b}+P_{t}+N P_{l}{ }_{P X}\left[{ }_{b}+P_{t}\right]\right)(1 \mathrm{RR})}{\mathrm{RR}_{b}}
\end{aligned}
$$

\subsection{CCRO configuration}

A diagram of the version of CCRO modelled here is shown in Fig. 2. In CCRO, brine is rejected only at the end of a cycle. However, to maintain constant system volume, feed enters the system throughout the cycle through the main pump (at the same rate that permeate exits the system) and mixes with the recirculated brine. A circulation pump counters viscous losses to drive flow throughout the system. The feed pressure rises over time as the osmotic pressure inside the membrane module increases.

\section{Figure 2. here}

\subsection{Batch configuration}

Entropy generation due to mixing of feed with recirculated brine in CCRO systems can be minimized by switching to a fully batch process. In such a process, feed enters only at the beginning of a cycle. It is circulated and concentrated over time, and then exits. In one implementation (shown in Fig. 3), a variable-volume, pressurized tank stores brine to be recirculated. The tank must vary in volume to accommodate permeate leaving the system. In another implementation, the tank can be integrated into the membrane module by means of a flexible bladder (Warsinger et al., 2016b), thus eliminating the need for a variable-volume high pressure tank. More detail of this configuration can be found in the appendix. 


\section{Figure 4. here}

Figure 4 depicts an alternative implementation that uses only existing components including a tank at atmospheric pressure and a pressure exchanger (Warsinger et al., 2016a). Part of the feed passes through the high pressure pump to maintain equal flow rates through the pressure exchanger. The slight increase in energy consumption due to replacement of a high pressure tank with a low pressure tank and pressure exchanger is discussed in Sec. 4.1.

\subsection{Batch RO and CCRO modeling}

Because of their extensive similarity, batch $\mathrm{RO}$ and CCRO are discussed together in this section.

Unlike the continuous RO model, both batch and CCRO models require discretization because salinity varies in both space and time. Efraty and Stover (Efraty et al., 2011, Stover, 2013b) address the temporal variation by dividing the CCRO process into a number of cycles, each of which appears to be modelled as standard (timeinvariant) $\mathrm{RO}$ at a recovery ratio equal to the module recovery ratio. Terminal osmotic pressure is calculated for each cycle and pressure is increased at the beginning of each cycle. In a real batch or CCRO system, feed pressure could be gradually and continuously increased during each cycle as the feed is concentrated, and terminal osmotic pressure may be lower than that predicted with steady-state assumptions. The model employed in this study should more accurately capture both temporal and spatial evolution of concentration, which is particularly relevant to energy consumption for low recovery ratios in CCRO and for all batch cases.

A discretization method was chosen to simplify modeling based on the assumption of fixed terminal hydraulic-osmotic pressure difference, $\Delta P_{t}$. If a fixed $\Delta P_{t}$ is assumed as in the continuous RO model, the process can be discretized by permeate produced. During each step forward, a small, fixed amount of permeate is removed from each subdivision of the module, and the water and salt remaining in each section move to the next section. Although the exact spatial salinity profile is not captured, this discretization method ensures that 
by the time a parcel of feed moves from the beginning to the end of the module, its volume has been reduced by a factor of $\left(1-R R_{m}\right)$, where $R R_{m}$ is the module recovery ratio, as shown in Fig. 5 .

\section{Figure 5. here}

Because the volume of feed is reduced in each step, the module must be discretized into unequal volumes as shown in Fig. 5 according to Eqs. (7)- (10). Each section is $\Delta V_{p} / n$ larger than the section that follows it because of the removal of permeate in each step. For an odd ${ }^{i}$ number of sections, $n$, the total module volume, $V_{m}$, can be related to the first section volume, $V_{1}$, as follows:

$$
V_{m}=\sum_{i=1}^{n} V_{i}=n V_{\frac{n-1}{2}}=n\left(V_{1}-\frac{n-1}{2} \frac{\Delta V_{p}}{n}\right)
$$

The permeate volume removed in each step, $\Delta V_{p}$, is the sum of the permeate volumes removed from all the sections during one step, while $V_{1}$ is the volume of feed entering the module during the same step.

By the definition of $R_{\mathrm{m}}$ :

$$
\Delta V_{p}=V_{1} \mathrm{RR}_{m}
$$

And Eq. (7) and (8) can be combined into Eq. (9) for the volume of the first section,

$$
V_{1}=\frac{V_{m}}{n-\frac{\operatorname{RR}_{m}(n-1)}{2}},
$$

and the volume of the $i^{\text {th }}$ section follows:

$$
V_{i}=V_{1}-i \Delta V_{p}
$$

In addition to the module volume, the batch system also has a variable-volume tank that's initial volume must be specified. The cost of the tank is assumed to increase with volume, so the tank volume is minimized as

\footnotetext{
${ }^{\mathrm{i}}$ Even numbers of sections are possible, but the formulation is simpler for odd $\mathrm{n}$.
} 
follows: for the batch system, the tank and module begin filled with feed; at the end of the cycle, a minimallysized tank would be empty, and the membrane module and piping would contain only brine . Therefore, the volume of the tank should be equal to the volume of permeate extracted in one cycle, and the volume of the membrane module and piping should be equal to the volume of brine produced in one cycle. Neglecting the volume of piping (in comparison to the module volume), the module and tank volumes can be related by the following equation:

$$
\frac{V_{m}}{V_{t}}=\frac{1-\mathrm{RR}}{\mathrm{RR}}
$$

A discrete salinity profile is calculated within the module over time. As water moves between sections, salt mass is conserved while water mass is reduced by $\rho_{p} \Delta V_{p}$, where $\rho_{p}$ is the pure water density. Changes in density due to the gradual concentration of the feed are neglected, as density increases by less than $3 \%$ over most of the salinity and recovery ratio range considered here. The osmotic pressure at the end of the module, $\pi_{n}$, is calculated from the salinity of the last section.

If $j$ is used to denote the permeate production step number $\left(j=V_{p}(t) / \Delta V_{p}\right)$, then the salt and water masses ( $m_{s, i, j}$ and $m_{w, i j}$, respectively) in the $i^{\text {th }}$ section during the $j^{\text {th }}$ step can be calculated as follows:

$$
\begin{aligned}
& m_{s, i, j}=\left\{\begin{array}{ll}
s_{1, j} V_{1} \rho_{f} & i=1 \\
m_{s, i-1, j-1} & i \neq 1
\end{array}\right. \text { and (12) } \\
& m_{w, i, j}=\left\{\begin{array}{cc}
\left(1-s_{1, j}\right) V_{1} \rho_{f} & i=1 \\
m_{w, i-1, j-1}-\frac{\rho_{p} \Delta V_{p}}{n} & i \neq 1
\end{array} . \quad\right. \text { (13) }
\end{aligned}
$$

These conservation equations result from the salt moving from section to section, and the water moving with it except for the portion removed as permeate from each section in each step. The local salinity, $s_{i, j}$, can then be calculated as the salt mass fraction:

$$
s_{i, j}=\frac{m_{s, i, j}}{m_{w, i, j}+m_{s, i, j}},
$$


and the maximum osmotic pressure in the module can be calculated using the Pitzer model (Pitzer, 1973)

based on the salinity in the last section:

$$
\pi_{n, j}=\left.\pi\right|_{s_{n, j}}
$$

The method of calculating the salinity of the solution entering the module, $s_{1, j}$, differs between the batch and CCRO processes. For the batch process, the concentrate leaving the membrane module is mixed with the solution in the tank. Equations (16) and (17) are salt and water mass balances, respectively, governing timeprogression of salinity in the discretized model for the batch process:

$$
\begin{aligned}
& m_{s, t, j}=m_{s, t, j-1}+m_{s, n, j-1}-m_{s, 1, j-1}, \text { and } \\
& m_{w, t, j}=m_{w, t, j-1}+m_{w, n, j-1}-m_{w, 1, j-1} .
\end{aligned}
$$

The salinity of the first section of the membrane, $s_{1, j}$, is then the salt mass fraction of the tank at step $j$.

For the CCRO process, feed is continually mixed with the concentrate to maintain a constant system volume as permeate is removed. Because the make-up feed flow rate into the system is equal to permeate flow rate, and constant density is assumed, the following salt and water balances can be applied at the mixing junction:

$$
\begin{gathered}
m_{s, 1, j}=m_{s, n, j-1}+V_{p} \rho_{f} s_{f}, \text { and } \\
m_{w, 1, j}=m_{w, n, j-1}+\left(1-s_{f}\right) V_{p} \rho_{f} .
\end{gathered}
$$

In both processes, the module is completely filled with feed in the initial state of the cycle, giving the conditions everywhere at $i=1$. This neglects streamwise mixing between the incoming feed and outgoing brine at the end of the cycle as well as any reverse permeation of water across the membrane during the time it takes 
to refill the module with feed. With this initial condition, the model has been described to the extent where salinity profiles can be calculated for the batch and CCRO processes.

Figure 6 shows example salinity profiles for CCRO and batch systems in order to illustrate the differences between these seemingly similar processes. These profiles are based on a feed salinity of $3 \mathrm{~g} / \mathrm{kg}$ and $75 \%$ recovery. In both processes, salinity increases in time everywhere. As in continuous RO, the CCRO salinity profile is monotonically increasing with distance at any given time. However, batch RO departs from this behavior as each cycle approaches its end. Although each parcel of fluid increases in salinity as it traverses the module, the spatial salinity profile in the module can have a minimum in the middle of the module. This occurs because concentrate from the module outlet returns to the tank and then to the feed. Near the end of the cycle, the tank volume is almost zero, so concentrate goes almost directly from the module outlet to the inlet again, causing the difference between inlet and outlet salinities to approach zero at each cycle's end. The energetic implications of this unusual salinity profile is discussed in Sec. 4.3.

\section{Figure 6. here}

Expressions for energy are developed based on the salinity progressions calculated with the models described above. Once the salinity at the end of the membrane module is calculated using the above model, the pressure at the module outlet is set to a fixed amount above the osmotic pressure of the last section of the membrane module. The feed entering the module inlet is then pumped in at the current osmotic pressure in the last section plus the terminal osmotic pressure difference and hydraulic pressure drop through the module, which is assumed to be 1 bar.

The energy consumption of the brine rejection step is assumed to be equal in the CCRO and batch processes, although the actual energy consumption will depend somewhat on the system design. Various methods have been proposed for emptying the module of brine and refilling it with feed. In the present model, a brine reject valve is opened fully and feed is pushed into the module at roughly atmospheric pressure, displacing the brine. 
Assuming negligible back-flux of permeate during the brine rejection step, the specific energy consumption of

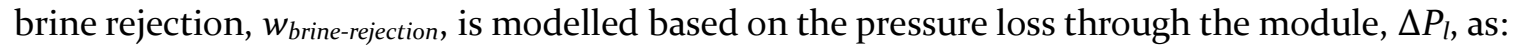

$$
w_{\text {brine-rejection }}=\frac{1-\mathrm{RR}}{\mathrm{RR}} \Delta P_{l} \text {. }
$$

This formulation of

brine rejection energy

consumption assumes that only the brine volume is pumped through the membrane module, and the remaining volume of feed is pumped directly into the tank.

The reversible work done by each pump can be calculated as the volume flow rate integral of the pump pressure. The total work done by pumps is then the sum of the reversible work consumption of each pump divided by its efficiency. In the discretized model, the integral is approximated by a sum over small permeate volume elements. Expansion of the pressure vessel during pressurization is neglected due to the high Young's modulus of steel.

In the batch process, energy consumption depends on whether the tank is maintained at the pressure of the feed or at atmospheric pressure. In the design with a high-pressure, variable-volume tank, the energy consumption per unit volume of permeate $\left(\mathrm{w}_{\text {batch,HP}}\right)$ is:

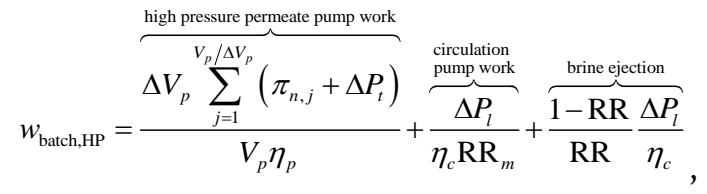

where $\eta_{p}$ and $\eta_{c}$ are the efficiencies of the high-pressure and circulation pumps. The pressure is summed over the permeate volume because only the permeate volume passes through the high-pressure pump in this design, while the circulation pump takes care of circulation through the system.

In the case where the tank is at atmospheric pressure and a pressure exchanger is utilized, some energy is lost in depressurization and pressurization. Modeling the pressure exchanger as in (Mistry et al., 2011), the energy consumption per unit permeate of the batch process with an atmospheric pressure tank, $w_{b a t c h, L P}$, is: 


$$
\begin{aligned}
& w_{\text {batch }, \mathrm{LP}}=\frac{\overbrace{\Delta V_{p} \sum_{j=1}^{V_{p} / \Delta V_{p}}\left(\pi_{n, j}+\Delta P_{t}+\Delta P_{l}\right)}^{\text {high pressure pump work }}}{V_{p} \eta_{p}}+ \\
& \text { booster pump work due to irreversible pressure exchange } \\
& \frac{1-\mathrm{RR}_{m}}{\mathrm{RR}_{m}} \frac{\Delta V_{p} \sum_{j=1}^{V_{p} / \Delta V_{p}}\left(\pi_{n}+\Delta P_{t}+\Delta P_{l}-\eta_{P X}\left(\pi_{n}+\Delta P_{t}\right)\right)}{V_{p} \eta_{b}}+\frac{\overbrace{1-\mathrm{RR}}^{\text {brine ejection }} \frac{\Delta P_{l}}{\eta_{p}}}{\mathrm{RR}}
\end{aligned}
$$

where $\eta_{b}$ is the efficiency of the booster pump needed after the pressure exchanger. Again, $j$ is the time step.

The energy consumption of the pressurized tank design is always lower due to the absence of irreversibilities in the pressure exchanger and booster pump. However, the design with an atmospheric pressure tank and pressure exchanger is presumed to be more practical in the short term because of its use of only existing components, so Eqn. (22) will be utilized for the batch case in the comparisons in Sec. 4.2.

In CCRO, the energy requirement per unit permeate, $w_{C C R O}$, is the feed volume integral of feed pressure (or, in this discretized case, the sum) plus the contributions from viscous losses during recirculation and brine ejection:

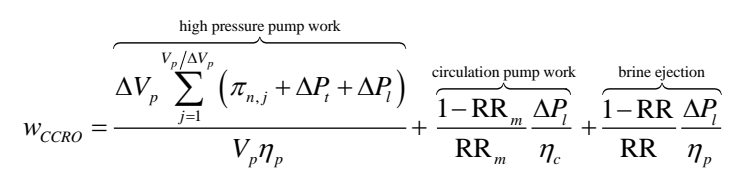

Batch and CCRO results are based on Eqs. (22) and (23) with the module divided into 101 sections $(n=101)$. In the absence of batch RO or CCRO experimental data, validation of these models will rely on comparison with the reported results of the CCRO model by Stover (Stover, 2012, Stover, 2013b) that discretizes the CCRO process into stages at different pressures and feed salinities. Table $\mathbf{1}$ here shows the comparison between the present CCRO model and that of Stover, using system parameters (shown in table) such as pump efficiency taken from the previous studies. The last two rows show the previous results and the present results for comparison. Although the results would not be expected to be exactly the same because of their differing approaches to simplifying the temporal and spatial concentration variations in CCRO, the degree of agreement (within 8-12 \% for all three comparisons) suggests that the discretization and solution method described herein is reasonable. Experimental data is needed to validate the batch RO model and further validate the CCRO model. It is worth 
noting that the simplistic assumption of constant pump efficiency may increase capital costs for batch processes as, in reality, pump efficiency changes as a function of the flow rate and head. More detailed modelling will be required to capture the effect of changes in pump efficiency during operation. It is hoped that the magnitude of energy savings predicted by the models for batch and CCRO processes over continuous RO will inspire future experimental research.

\section{Table 1 here}

Energy consumption calculations presented in the following section are based on $30 \%$ module recovery ratio, hydraulic pressure loss of $\Delta P_{l}=1$ bar, terminal hydraulic-osmotic pressure difference of $\Delta P_{t}=5$ bar, and pump efficiencies of $80 \%$. When relevant, pressure exchanger efficiency is modelled as $96 \%$.

\section{RESULTS AND DISCUSSION}

\subsection{Energy use}

The energy requirements of the systems modelled in this work are compared in this section. Figure 7 shows energy consumption as a function of recovery ratio for $3 \mathrm{~g} / \mathrm{kg} \mathrm{NaCl}$ feed based on the models in Sec. 3.5. Least work of separation (Nayar et al., 2015, Thiel et al., 2015) is also included for comparison.

\section{Figure 7. here}

Figure 7 shows that the time-variant systems are less energy-intensive than continuous RO with or without energy recovery, and that the improvements are more pronounced at high recovery. The high pressure tank variant ("batch + HP tank") of batch RO consumes the least energy across all recovery ratios higher than 40.1\%, although the batch variant with a pressure exchanger ("batch + PX") performs very similarly. At lower recovery, CCRO and both batch technologies perform similarly because the entropy generation due to mixing is minimal in both systems. However, at $80 \%$ recovery, even the batch variant with a pressure exchanger (the less efficient design) uses $9 \%$ less energy than CCRO. As recovery increases to $90 \%$, as it might in the RO step of zero liquid discharge applications, CCRO and batch RO with a pressure exchanger reduce energy use by $34 \%$ and $53 \%$, respectively, compared to continuous $\mathrm{RO}$ with a pressure exchanger. 
Although the least work of separation increases monotonically with recovery ratio, Fig. 7 shows that the actual energy consumption of continuous RO without energy recovery reaches a minimum around 6o \% recovery. This trend results from throttling of high pressure brine as it leaves the system. At low recovery ratios, a larger amount of fluid is irreversibly depressurized per unit permeate than at high recovery ratios. While energy recovery devices can replace throttles and recover part of the loss, the time-variant systems reduce energy consumption by only pumping the permeate volume to high pressure, thus eliminating the need to (irreversibly) recover energy from the brine. This distinction is discussed further in Sec. 4.3.

\subsection{System efficiency comparison}

Exergy efficiencies of continuous RO, CCRO, and batch RO are compared to highlight differences among these designs (Fig. 8 and Fig. 9). Exergy efficiency is defined as the ratio of least work to actual work, where least work is a function of the salinity and recovery ratio ${ }^{\text {ii }}$ as given in (Thiel et al., 2015). Figure 8 shows the exergy efficiency of continuous $\mathrm{RO}$ with pressure recovery, $\mathrm{CCRO}$, and batch $\mathrm{RO}$ with an atmospheric pressure tank as a function of salinity and recovery ratio iii. Results are capped at $100 \mathrm{~g} / \mathrm{kg}$ brine salinity, which is slightly above the ratings of state of the art seawater RO systems, but achievable with some modifications (Thiel et al., 2015). All three systems have higher efficiency at higher feed salinity because the least work of separation rises while the losses stay relatively fixed, but the effect of recovery varies between them. Continuous RO with pressure recovery has its highest efficiency at lower recovery ratios. CCRO efficiency is relatively insensitive to recovery at low recovery ratios, but then drops sharply with increasing recovery. Only batch systems demonstrate increasing efficiency with increasing recovery across the entire modelled range. At lower recoveries and lower salinities, CCRO and batch RO are nearly identical. As a result, both CCRO and batch RO are energetically

\footnotetext{
ii Zero salt permeation is assumed.
} 
superior choices to continuous RO at low recovery. Batch RO is the most energy efficient of the three systems at high recovery. At most lower recovery ratios, CCRO and batch systems perform similarly. Only at the lowest salinities and recovery ratios (which would rarely be a desirable combination) is continuous RO the most efficient choice. Figure 9 maps these relative advantages over a range of salinities and recovery ratios.

Figure 8. here

\section{Figure 9. here}

\subsection{Sources of energy savings}

Examination of the drivers of energy consumption in these systems explains the trends seen in Figs. 7-9. RO energy consumption is the sum of several contributions: reversible work, inefficiencies in components such as pumps, irreversible mixing, excess pressure to drive flux, brine throttling, and viscous friction (Sharqawy et al., 2011). For a given feed composition and desired recovery ratio, the reversible work is fixed, and both component efficiencies and viscous friction were kept constant between the different system models in this work (Sharqawy et al., 2011). Therefore, the differences in energy consumption come down to three main factors that differ between the system designs: brine throttling, excess pressure, and irreversible mixing.

Whereas continuous RO requires the entire feed volume to be pumped up to high pressure, the CCRO and batch systems displace brine at atmospheric pressure and require only the permeate volume to pass through a pump, leading to significant energy savings, especially at lower recovery. The losses from rejecting highpressure brine unique to continuous RO can be significantly reduced by adding energy or pressure recovery to the continuous RO system (Banchik and Lienhard, 2012, Voutchkov, 2012), as is evident in Fig. 7. This is almost always done in seawater plants, but because the pump and energy recovery device are not ideal, there is still additional energy consumption associated with pressurizing and depressurizing the brine volume in continuous RO. 
Excess pressure above the osmotic pressure also varies between time-variant and continuous RO systems. In continuous $\mathrm{RO}$, the pressure is nearly uniform throughout the membrane module (and, in the absence of booster pumps, throughout the train). In batch $\mathrm{RO}$ and $\mathrm{CCRO}$, the pressure in the module is roughly uniform at any given time, but it can start low and be continually raised as the osmotic pressure at the module outlet increases. At low recoveries comparable to the module recovery, the excess pressure does not contribute significantly to the difference in energy consumption between technologies, but the effect of this difference rises with increasing recovery.

To illustrate this concept, Fig. 10 compares the pressure profiles of ideal continuous RO, CCRO, and batch systems in the limit of zero membrane resistance, concentration polarization, viscous losses, and module recovery ratio. Whereas the time-variant processes have the ability to stay close to the osmotic pressure curve, the pressure in continuous $\mathrm{RO}$ is required to be at or above the osmotic pressure of the discharged brine everywhere. Between CCRO and batch systems, the shape of the osmotic pressure profiles within a module of finite recovery also contributes to the difference in energy consumption. The osmotic pressure in CCRO rises almost linearly with instantaneous recovery ratio because salt is added to the system constantly with the feed, with a flow rate matching the rate of permeate production. As shown previously in Fig. 6 and discussed in Sec 3.5, the variation in osmotic pressure within the module is lower for the batch system, which reduces its energy consumption. In the present comparison, terminal osmotic-hydraulic pressure difference, rather than membrane area, is fixed, so the model may overestimate differences in energy consumption seen between steady and transient systems. However, in a treatise on thermodynamic balancing (Thiel et al., 2014), Thiel et al. show significant energy savings due to a uniform osmotic-hydraulic pressure difference in a batch RO process over a constant pressure design, even when the membrane area is fixed.

\section{Figure 1o. here}

Finally, and most subtly, the energy consumption of the two transient systems are differentiated by the level of irreversible mixing. In the batch process, solution leaving the membrane module returns to the tank at a concentration higher than the solution in the tank. When these streams of different concentration mix, entropy 
is generated and potentially recoverable work is lost. This increases the energy consumption of the system.However, as can be seen from the salinity profiles in Fig. 6, for batch RO the salinity difference between the streams being mixed (the beginning and end of any given salinity curve) is not very large, so the losses due to this mixing process are small. In CCRO, the solution leaving the membrane module is mixed not with the tank liquid but with fresh feed. As the feed salinity is always less than or equa to the tank salinity in the batch RO case, the entropy generation due to mixing in CCRO is greater than in the batch process. The difference in entropy generation from mixing increases with RR, as can be seen from the increasing difference between batch and CCRO osmotic pressure profiles in Fig. 10 as recovery ratio is increased from $45 \%$ to $85 \%$. This source of energy savings in batch systems over CCRO is reflected in the divergence in energy requirements at high recoveries shown in Fig. 7 .

Work lost due to mixing in both batch and CCRO systems was calculated with the discretized model at a feed salinity of $3 \mathrm{~g} / \mathrm{kg}$ and was shown to correlate strongly with actual energy consumption in Fig. 11. Work lost is equivalent to the entropy generation due to mixing divided by the ambient temperature in $\mathrm{K}$, and it is normalized by permeate volume in Fig. 12. The difference in energy requirements between batch and semibatch RO correlates strongly with the difference in work lost to irreversible mixing, which is more significant at higher recovery ratios. Mixing work lost and thus mixing entropy generation are significantly reduced by the transition from semi-batch to batch systems.

Fig. 11. here

\section{CONCLUSIONS}

This work demonstrates that batch and semi-batch RO processes may be expected to achieve performance superior to continuous processes. The work also describes batch configurations achievable with existing technologies. Numerical models have been used to compare the energy requirements of batch RO, closedcircuit reverse osmosis, and continuous reverse osmosis with and without pressure recovery. The results 
demonstrate that batch and semi-batch RO processes provide significant reduction of energy use in relevant regimes of feed salinity and recovery ratio.

Two primary conclusions were reached in this study:

- Both batch and semi-batch RO systems show substantial efficiency improvements over continuous RO, especially at high recovery ratio (>75\%) and higher salinities (>10 g/kg).

- At very high recovery ratios, the two proposed configurations of batch $\mathrm{RO}$ achieve significantly higher efficiency than the semi-batch process. This gain is possible because batch processing avoids mixing of recirculating brine with fresh feed, as occurs in the semi-batch (CCRO) process.

Future studies of batch RO should aim to experimentally validate the proposed model, verify the magnitude of attainable energy savings, and optimize system design for economical and efficient operation.

\section{ACKNOWLEDGMENT}

This work was funded by the Cooperative Agreement between the Masdar Institute of Science and Technology, Abu Dhabi, UAE and the Massachusetts Institute of Technology (MIT), Cambridge, MA,USA, Reference No. 02/MI/MI/CP/11/o7633/GEN/G/oo. EWT would like to thank The Martin Fellowship for Sustainability and acknowledge that this material is based upon work supported by the National Science Foundation Graduate Research Fellowship Program under Grant No. 1122374. We would also like to thank Margaret M. Bertoni, Ronan K. McGovern, and Gregory P. Thiel for useful discussions.

\section{NOMENCLATURE}

$i \quad$ Section number within membrane module [-]

$m \quad$ Mass $[\mathrm{kg}]$

$n \quad$ Number of sections in discretized membrane module [-]

$N \quad$ Number of stages [-]

RR Recovery ratio [-] 
$\mathrm{RR}_{m} \quad$ Module recovery ratio [-]

$s \quad$ Salinity $[\mathrm{g} / \mathrm{kg}]$

$V \quad$ Volume $\left[\mathrm{m}^{3}\right]$

$\dot{V} \quad$ Volume flow rate $\left[\mathrm{m}^{3} / \mathrm{s}\right]$

$w \quad$ Specific energy consumption [J/kg permeate]

$\Delta P_{l} \quad$ Viscous pressure drop per stage [Pa]

$\Delta P_{t} \quad$ Terminal hydraulic-osmotic pressure difference [Pa]

$\Delta V_{p} \quad$ Permeate volume produced in one step [ $\left.\mathrm{m}^{3}\right]$

$\eta \quad 2^{\text {nd }}$ law efficiency [-]

$\pi \quad$ Osmotic pressure $[\mathrm{Pa}]$

$\rho \quad$ Density $\left[\mathrm{kg} / \mathrm{m}^{3}\right]$

\section{Subscripts}

B Booster pump

$b \quad$ Brine

C Circulation pump

ERD Energy recovery device

$f \quad$ Feed

$H \quad$ High pressure pump

$i \quad i^{\text {th }}$ section of membrane

$j \quad j^{\text {th }}$ permeate removal step

m module

$n \quad$ Last section of membrane

p Permeate

$P X \quad$ Pressure exchanger

$R \quad$ Energy recovery device

$s \quad$ Salt 
Tank

w Water 


\section{Appendix: Single-vessel batch RO design}

\section{Figure 12 here}

Figure 12 shows a sample configuration [see (Warsinger et al., 2016b)] of a fully-batch RO system in which the variable-volume tank is incorporated into the main pressure vessel. As permeate is produced, it is pumped into a flexible permeate bladder within the pressure vessel. The displaced volume leaves through the membranes as permeate, while the external circulation pump drives flow through the membrane feed channels to reduce concentration polarization. Because only the permeate volume must be pumped across a large pressure difference, this batch system can realize significant energy savings.

\section{REFERENCES}

[Banchik and Lienhard, 2012] Banchik, L. D. and Lienhard, J. H. (November 9-15, 2012). Thermodynamic analysis of a reverse osmosis desalination system using forward osmosis for energy recovery. In Proceedings of ASME 2012 International Mechanical Engineering Congress and Exposition, Paper No. IMECE2012-86987, Houston, TX. American Society of Mechanical Engineers.

[Barello et al., 2015] Barello, M., Manca, D., Patel, R., and Mujtaba, I. (2015). Operation and modeling of RO desalination process in batch mode. Computers \& Chemical Engineering, 83:139-156.

[Bratt, 1989] Bratt, R. I. (1989). Water treatment. US Patent 4,814,086.

[Chang et al., 2008] Chang, Y. J., Reardon, D. J., Kwan, P., Boyd, G., Brant, J., Rakness, K. L., and Furukawa, D. (2008). Evaluation of dynamic energy consumption of advanced water and wastewater treatment technologies. Technical report, AWWA Research Foundation.

[Efraty et al., 2011] Efraty, A., Barak, R. N., and Gal, Z. (2011). Closed circuit desalination - a new low energy high recovery technology without energy recovery. Desalination and Water Treatment, 31(1-3):95-101. 
[Greenlee et al., 2009] Greenlee, L. F., Lawler, D. F., Freeman, B. D., Marrot, B., and Moulin, P. (20o9). Reverse osmosis desalination: water sources, technology, and today's challenges. Water research, 43(9):2317-2348.

[Kundzewicz et al., 2008] Kundzewicz, Z. W., Mata, L. J., Arnell, N. W., Doll, P., Jimenez, B., Miller, K., Oki, T., Sen, Z., and Shiklomanov, I. (2008). The implications of projected climate change for freshwater resources and their management. Hydrological Sciences Journal, 53(1):3-10.

[Lazarova et al., 2012] Lazarova, V., Choo, K.-H., and Cornel, P. (2012). Water-energy interactions in water reuse. IWA Publishing.

[Lin and Elimelech, 2015] Lin, S. and Elimelech, M. (2015). Staged reverse osmosis operation: Configurations, energy efficiency, and application potential. Desalination, 366:9-14.

[Liu et al., 2011] Liu, C., Rainwater, K., and Song, L. (2011). Energy analysis and efficiency assessment of reverse osmosis desalination process. Desalination, 276(1):352-358.

[McCool et al., 2010] McCool, B. C., Rahardianto, A., Faria, J., Kovac, K., Lara, D., and Cohen, Y. (2010). Feasibility of reverse osmosis desalination of brackish agricultural drainage water in the San Joaquin Valley. Desalination, 261(3):240-250.

[Mekonnen and Hoekstra, 2016] Mekonnen, M. M. and Hoekstra, A. Y. (2016). Four billion people facing severe water scarcity. Science Advances, 2(2).

[Miller, 2003] Miller, J. E. (2003). Review of water resources and desalination technologies. Technical Report SAND 2003-o8oo, Sandia National Laboratories, Livermore, CA.

[Mistry et al., 2011] Mistry, K. H., McGovern, R. K., Thiel, G. P., Summers, E. K., Zubair, S. M., and Lienhard, J. H. (2011). Entropy Generation Analysis of Desalination Technologies. Entropy, 13(10):1829-1864.

[Nayar et al., 2015] Nayar, K. G., Wright, N. C., Thiel, G. P., Warsinger, D. M., Winter V, A. G., and Lienhard, J. H. (2015). Energy requirements of alternative technologies for desalinating groundwater for irrigation. In International Desalination Association World Congress 2015, San Diego, USA.

[Oki and Kanae, 2006] Oki, T. and Kanae, S. (2006). Global hydrological cycles and world water resources. Science, 313(5790):1068-1072.

[Oklejas Jr, 2011] Oklejas Jr, E. (2011). Batch-operated reverse osmosis system with manual energization. US Patent $7,892,429$.

[Oklejas Jr, 2014] Oklejas Jr, E. (2014). Batch-operated reverse osmosis system. US Patent 8,808,538. 
[Pangarkar et al., 2011] Pangarkar, B. L., Sane, M. G., and Guddad, M. (2011). Reverse Osmosis and Membrane Distillation for Desalination of Groundwater: A Review. ISRN Materials Science, 2011:1-9.

[Pelmulder, 1981] Pelmulder, J. P. (1981). Water purification process and system. US Patent 4,243,523.

[Pitzer, 1973] Pitzer, K. S. (1973). Thermodynamics of electrolytes. I. Theoretical basis and general equations. The Journal of Physical Chemistry, 77(2):268-277.

[Qiu and Davies, 2012] Qiu, T. and Davies, P. (2012). Longitudinal dispersion in spiral wound RO modules and its effect on the performance of batch mode RO operations. Desalination, 288:1 - 7 .

[Richey et al., 2015] Richey, A. S., Thomas, B. F., Lo, M.-H., Reager, J. T., Famiglietti, J. S., Voss, K., Swenson, S., and Rodell, M. (2015). Quantifying renewable groundwater stress with grace. Water Resources Research, 51(7):5217-5238.

[Semiat, 2008] Semiat, R. (2008). Energy issues in desalination processes. Environmental science E technology, $42(22): 8193-8201$.

[Sharqawy et al., 2011] Sharqawy, M. H., Zubair, S. M., and Lienhard, J. H. (2011). Second law analysis of reverse osmosis desalination plants: An alternative design using pressure retarded osmosis. Energy, 36(11):6617-6626.

[Stover, 2012] Stover, R. (2012). Evaluation of closed circuit reverse osmosis for water reuse. In Proc. 27th Annual Water Reuse Symp., Hollywood, FL, USA, September, Water Reuse Association, Paper B4-2.

[Stover, 2013a] Stover, R. L. (2013a). Industrial and brackish water treatment with closed circuit reverse osmosis. Desalination and Water Treatment, 51(4-6):1124-1130.

[Stover, 2013b] Stover, R. L. (2013b). Permeate recovery and flux maximization in semibatch reverse osmosis. IDA Journal of Desalination and Water Reuse, 5(1):10-14.

[Szucz and Szucs, 1991] Szucz, L. and Szucs, A. (1991). Method and apparatus for treating fluids containing foreign materials by membrane filter equipment. US Patent 4,983,301.

[Thiel et al., 2014] Thiel, G. P., McGovern, R. K., Zubair, S. M., and Lienhard, J. H. (2014). Thermodynamic equipartition for increased second law efficiency. Applied Energy, 118:292 - 299.

[Thiel et al., 2015] Thiel, G. P., Tow, E. W., Banchik, L. D., Chung, H. W., and Lienhard, J. H. (2015). Energy consumption in desalinating produced water from shale oil and gas extraction. Desalination, 366:94 - 112.

[Tow et al., 2015] Tow, E. W., McGovern, R. K., and Lienhard, J. H. (2015). Raising forward osmosis brine concentration efficiency through flow rate optimization. Desalination, 366:71 - 79 .

[Tribus and Evans, 1963] Tribus, M. and Evans, R. (1963). The thermoeconomics of seawater conversion. Engineering. Dept., Report No. 62-53, 
[V et al., 2017] V, J. L., Mistry, K., Sharqawy, M., and Thiel, G. (2017). Desalination Sustainability: A Technical, Socioeconomic, and Environmental Approach,, chapter Thermodynamics, Exergy, and Energy Efficiency in Desalination Systems. Elsevier Publishing Co.

[Voutchkov, 2012] Voutchkov, N. (2012). Energy use of seawater desalination-current status and future trends. IWA Publishing, London.

[Warsinger et al., 2016a] Warsinger, D. E. M., Lienhard, J. H., and Tow, E. W. (2016a). Batch pressure-driven membrane desalination using pressure exchanger for efficiency (provisional patent application).

[Warsinger et al., 2016b] Warsinger, D. E. M., Lienhard, J. H., Tow, E. W., McGovern, R. K., and Thiel, G. P. (2016b). Batch pressure-driven membrane desalination with closed flow loop and reservoir tank (provisional patent application).

[Warsinger et al., 2015] Warsinger, D. M., Mistry, K. H., Nayar, K. G., Chung, H. W., and Lienhard, J. H. (2015). Entropy generation of desalination powered by variable temperature waste heat. Entropy, 17:7530-7566.

[Warsinger et al., 2014] Warsinger, D. M., Swaminathan, J., and Lienhard, J. H. (Kyoto, Japan August 2014). Effect of module inclination angle on air gap membrane distillation. In Proceedings of the 15th International Heat Transfer Conference, IHTC-15, Paper No. IHTC15-9351.

[Yarlagadda et al., 2011] Yarlagadda, S., Gude, V. G., Camacho, L. M., Pinappu, S., and Deng, S. (2011). Potable water recovery from As, U, and F contaminated ground waters by direct contact membrane distillation process. Journal of Hazardous Materials, 192(3):1388-94. 
Table 1. Validation of the present CCRO model against those of Stover (Stover, 2012, Stover, 2o13b)

\begin{tabular}{|c|c|c|c|}
\hline Staged model and RR & $\begin{array}{l}\text { Stover } \\
\text { (Stover, 2012), } \\
\text { RR }=90 \%\end{array}$ & $\begin{array}{l}\text { Stover } \\
\text { (Stover, 2012), } \\
\text { RR = } 95 \%\end{array}$ & $\begin{array}{l}\text { Stover } \\
\text { (Stover, 2013b), } \\
\text { RR = 88\% }\end{array}$ \\
\hline \multicolumn{4}{|l|}{ Inputs } \\
\hline Feed TDS & $1.8 \mathrm{~g} / \mathrm{kg}$ & $1.8 \mathrm{~g} / \mathrm{kg}$ & $2.9 \mathrm{~g} / \mathrm{kg}$ \\
\hline $\mathrm{RR}_{\mathrm{m}}^{\mathrm{iv}}$ & $20 \%$ & $20 \%$ & $44 \%$ \\
\hline$\Delta \mathrm{P}_{\mathrm{t}}$ & 0.6 bar & 0.5 bar & 1.03 bar \\
\hline Efficiency of pumps & $70 \%$ & $70 \%$ & $70 \%$ \\
\hline \multicolumn{4}{|l|}{ Energy consumption } \\
\hline $\begin{array}{l}\text { Staged model 'Stover, 2012' } \\
\text { Stover, 2013b)(Stover, 2012' } \\
\text { Stover, 2013b) }\end{array}$ & $\begin{array}{c}\mathbf{0 . 4 1} \\
\mathrm{kWh} / \mathrm{m}^{3}\end{array}$ & $\begin{array}{c}0.63 \\
\mathrm{kWh} / \mathrm{m}^{3}\end{array}$ & o.67 kWh $/ \mathrm{m}^{3}$ \\
\hline Present model (Eq. (23)) & $\begin{array}{c}0.36 \\
\mathrm{kWh} / \mathrm{m}^{3}\end{array}$ & $\begin{array}{c}0.68 \\
\mathrm{kWh} / \mathrm{m}^{3}\end{array}$ & $0.59 \mathrm{kWh} / \mathrm{m}^{3}$ \\
\hline
\end{tabular}

iv $\mathrm{RR}_{\mathrm{m}}$ calculated from parameters given in (Stover, 2012) as (feed flow rate - recirculation flow rate) / feed flow rate and (Stover, $2013 \mathrm{~b}$ ) as 1 - (cycle TDS in / cycle TDS out) 


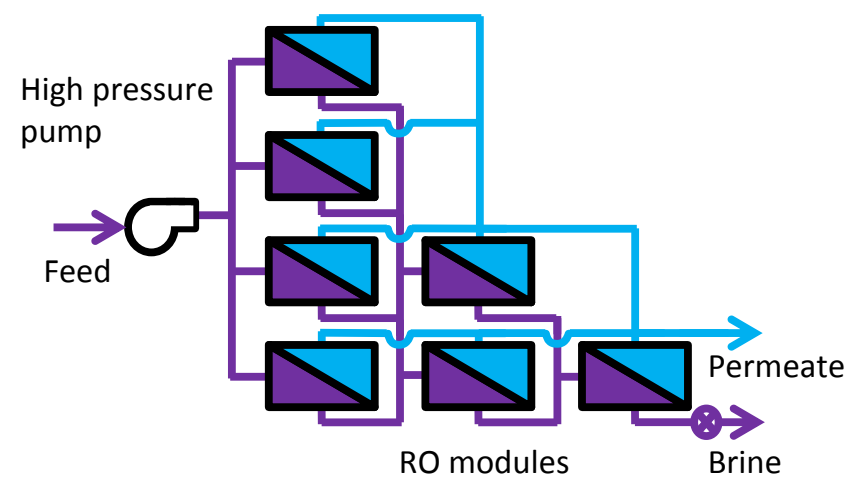

Figure 1. Train of RO modules for high recovery. 


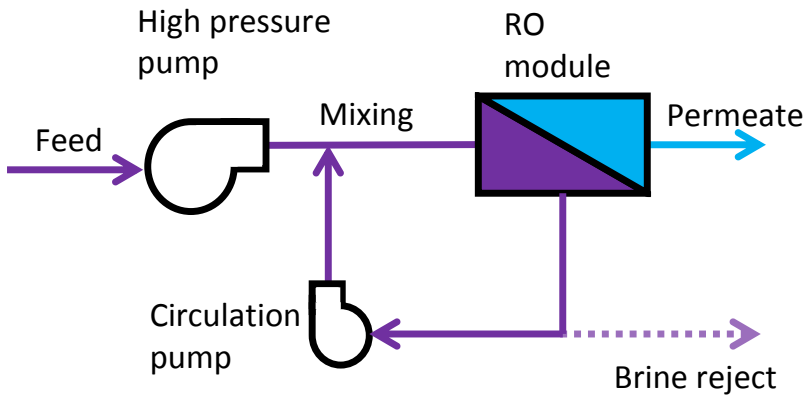

Figure 2. Schematic diagram of a closed-circuit reverse osmosis system. Feed continuously enters the system, but brine is rejected only at the end of the cycle. Pressure gradually increases over time. Dotted lines represent flows present only between cycles. 


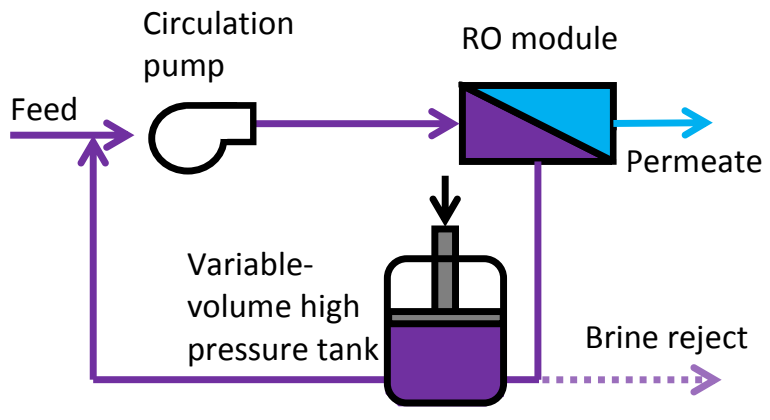

Figure 3. Schematic diagram of a batch RO system with a high pressure, variable-volume tank. In each cycle, the system is initially filled with feed, which is then circulated and concentrated over time. Brine is finally rejected at atmospheric pressure. Dotted lines represent flows present only between cycles. 


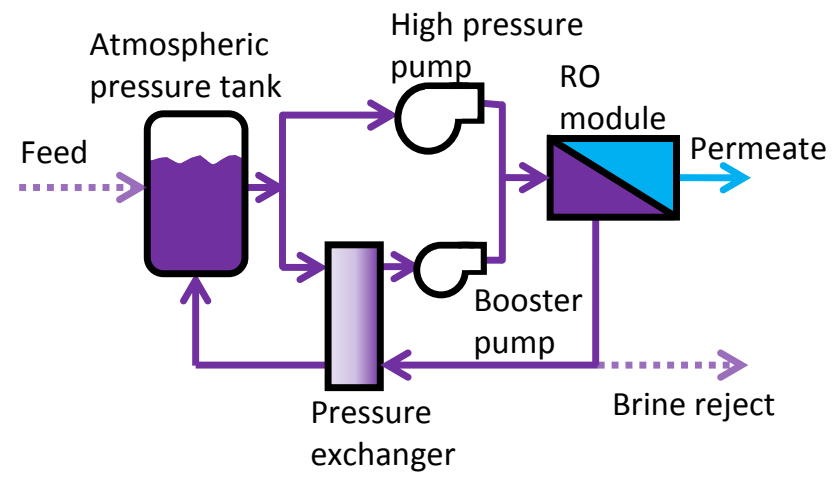

Figure 4. Alternative batch RO design, in which a pressure exchanger is used to reduce the pressure of the recirculating stream so that a standard, low-pressure tank can be used. 


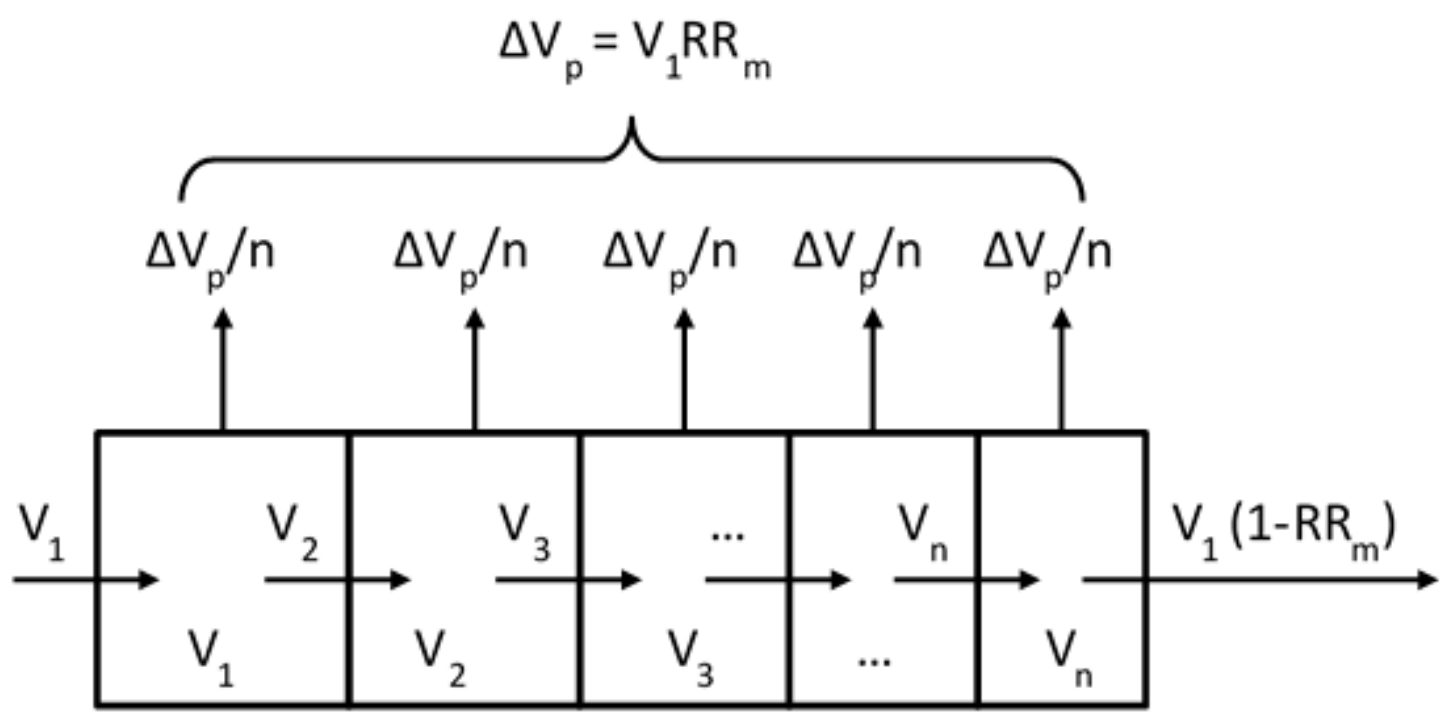

Figure 5. Volume discretization of membrane module for batch and CCRO models. The module is divided into unequal volumes, and in each step, equal amounts of permeate are removed from each section and the remaining liquid moves to the next section. 

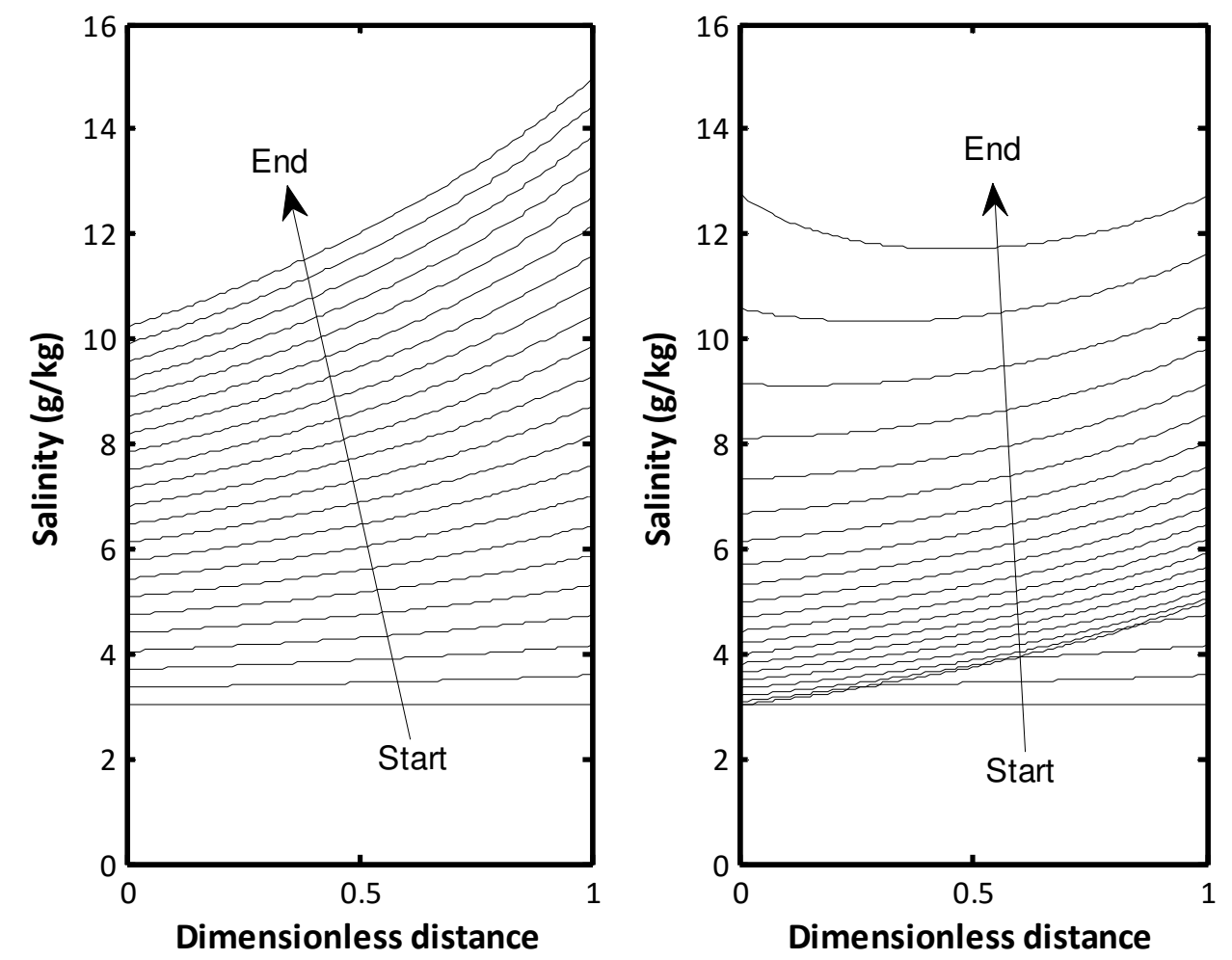

Figure 6. Alternative batch RO design with a variable volume tank. In this variant, a pressure exchanger is used to reduce the pressure of the recirculating stream so that a standard, low-pressure tank can be used. 


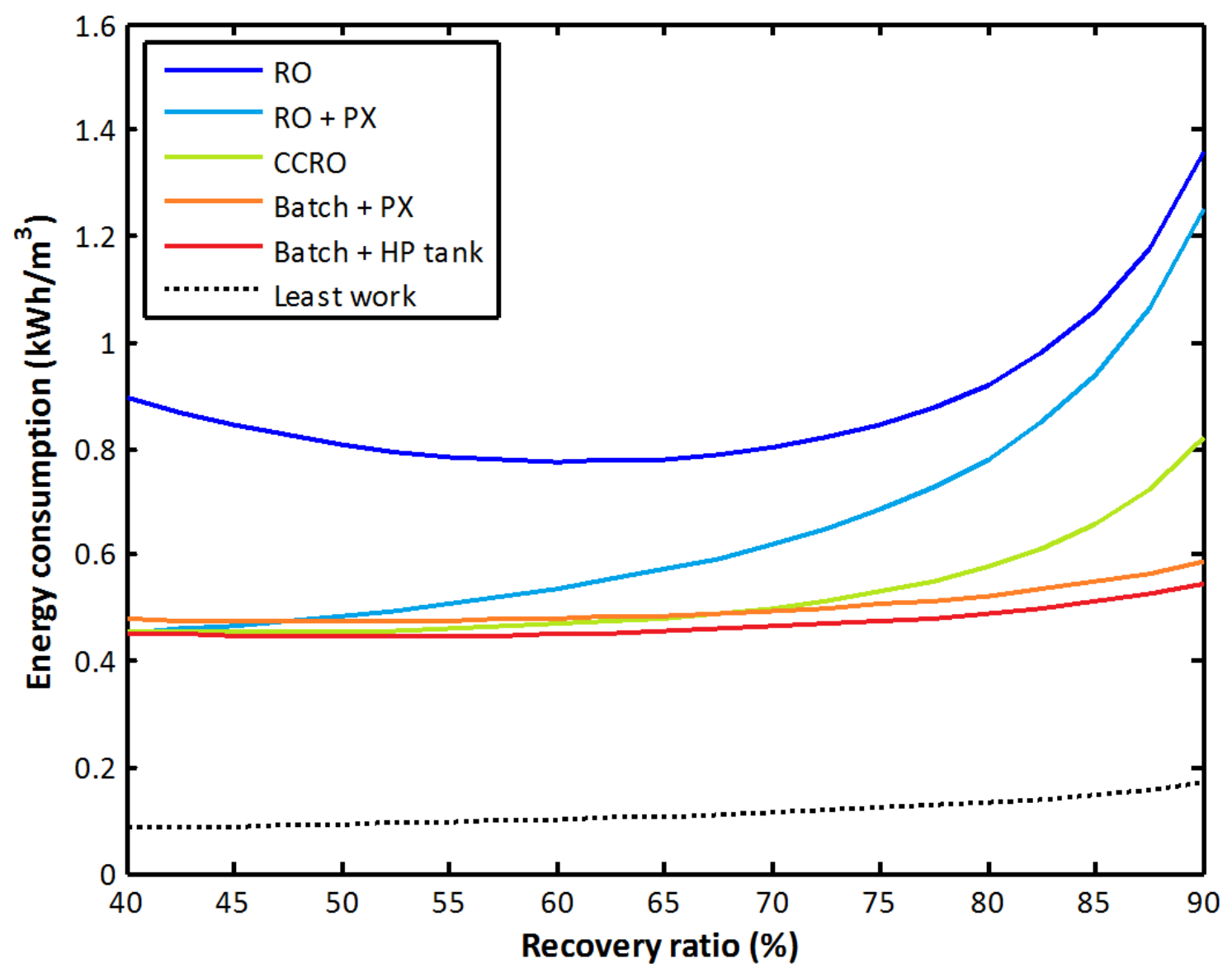

Figure 7. Modelled energy consumption of continuous and time-variant RO configurations for various recovery ratios with $3 \mathrm{~g} / \mathrm{kg} \mathrm{NaCl}$ feed. Least work of separation is also shown. PX stands for pressure exchanger and HP for high pressure. 

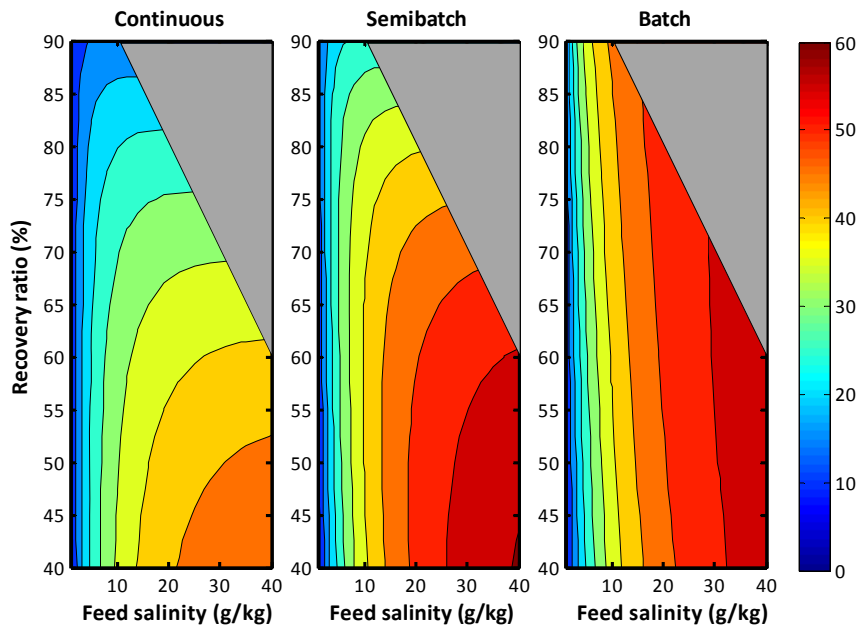

Figure 8. Exergetic efficiency (in \%) for continuous (with pressure recovery), semi-batch (CCRO), and batch RO systems. Grey regions indicate brine salinity over 100 ppt. 

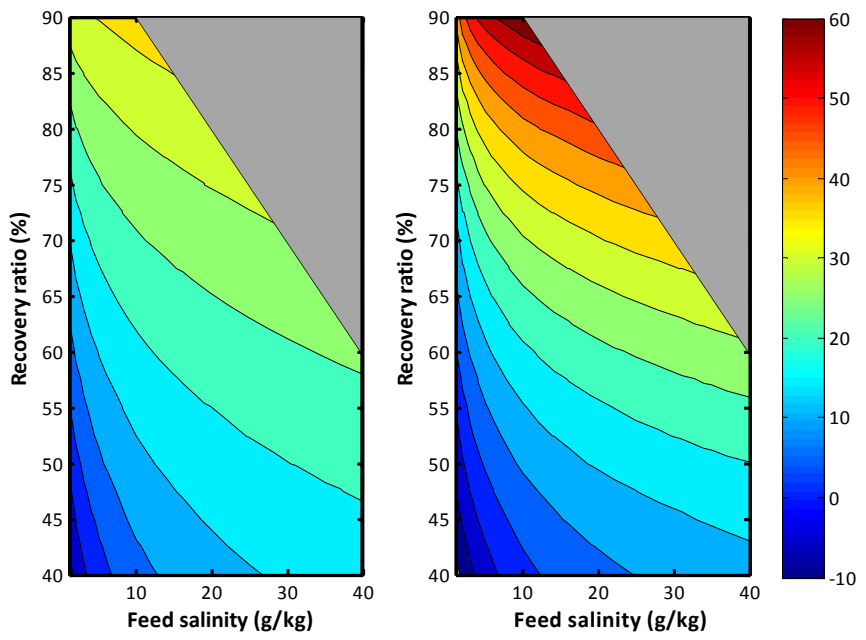

Figure 9. Percent reduction in energy requirements of (left) CCRO and (right) batch RO systems compared to continuous, single-stage RO with pressure recovery. Grey regions indicate brine salinity over 100 ppt. 

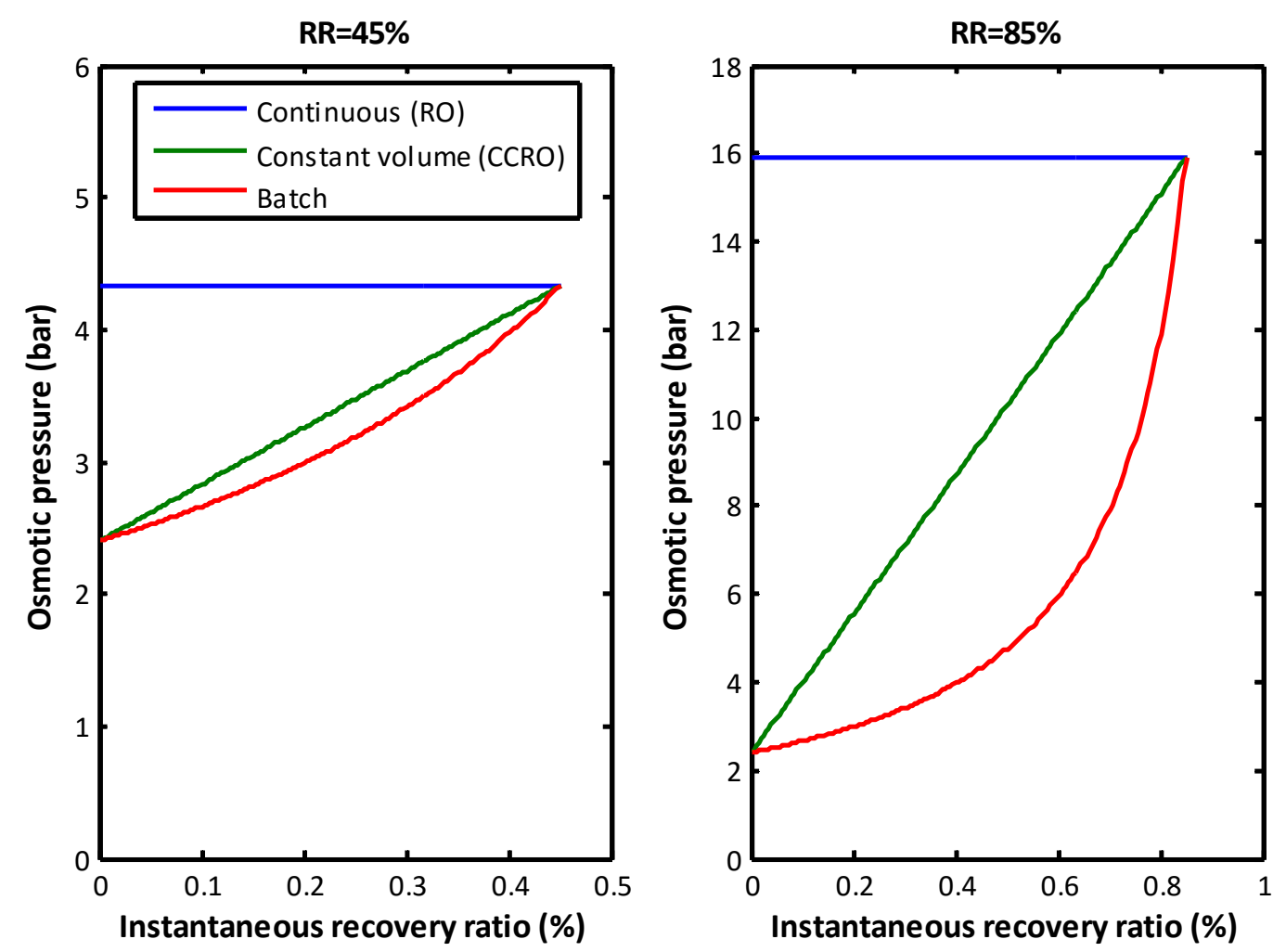

Figure 10. Minimum osmotic pressure at the module outlet vs. instantaneous recovery ratio for ideal continuous $\mathrm{RO}$, constant volume (semi-batch) RO, and batch $\mathrm{RO}$ processes for $3 \mathrm{ppt} \mathrm{NaCl}$ feed and recovery ratios of (a) $45 \%$ and (b) $85 \%$. 


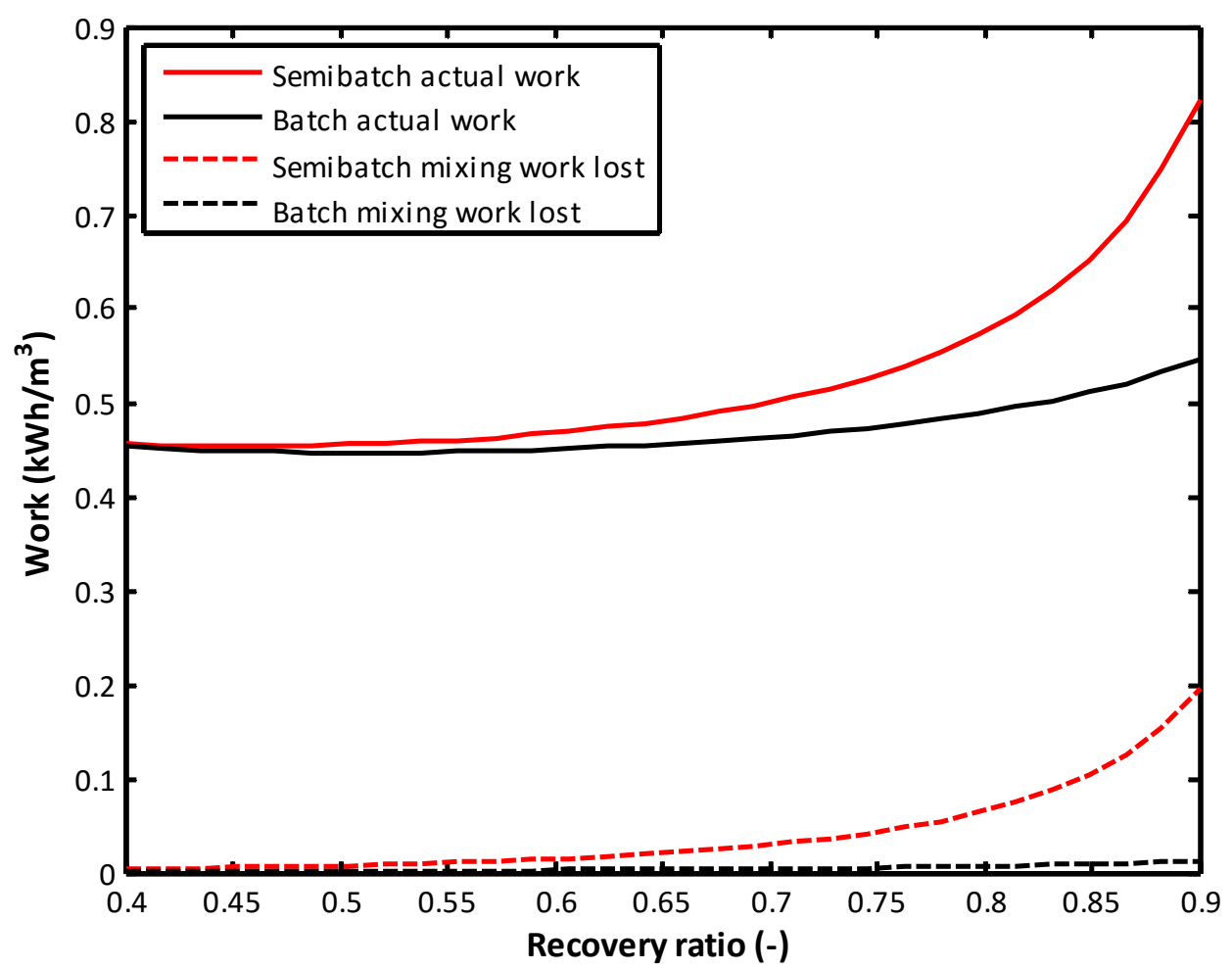

Figure 11. The difference in actual energy consumption is slightly greater than the difference in lost work because of the compounding effect of component (e.g., pump) inefficiencies. 
Batch designs reduce energy consumption up to $64 \%$ vs. continuous RO
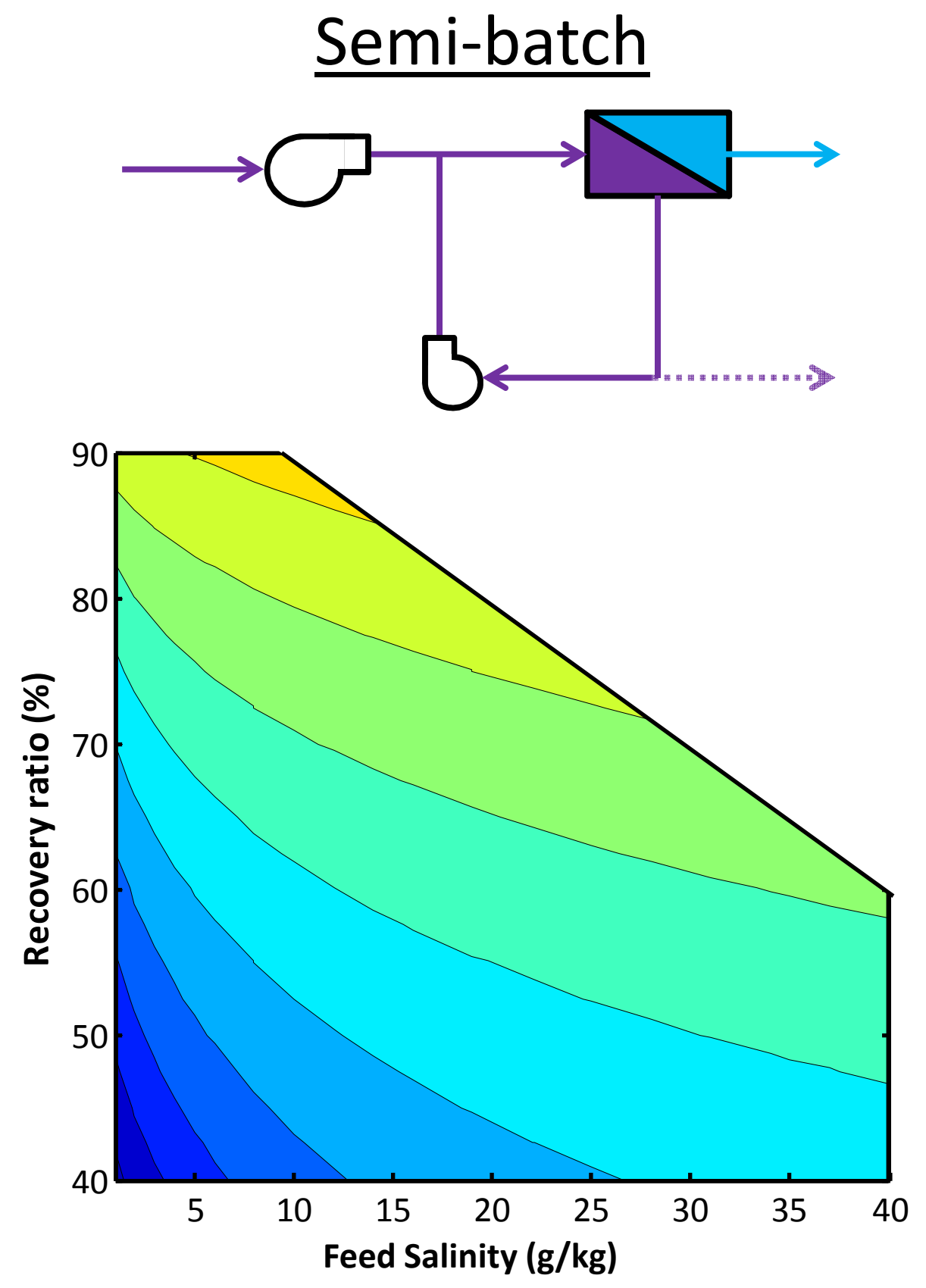

Semi-batch
Energy use reduction (\%)

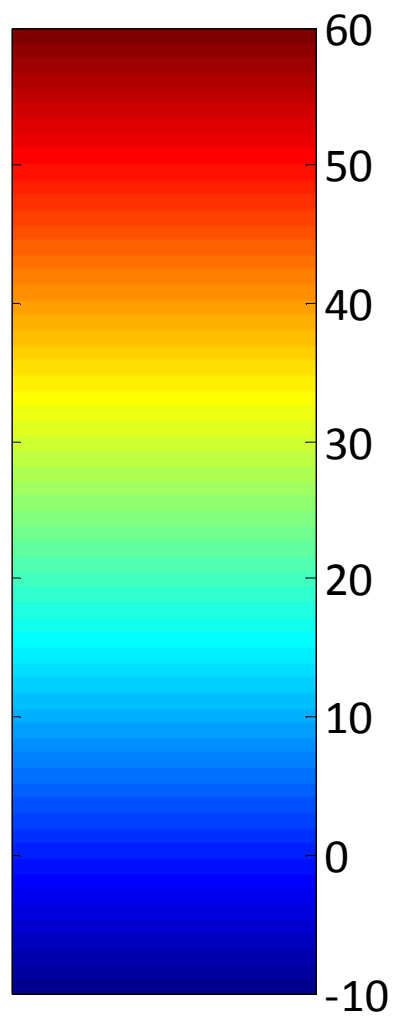

Batch
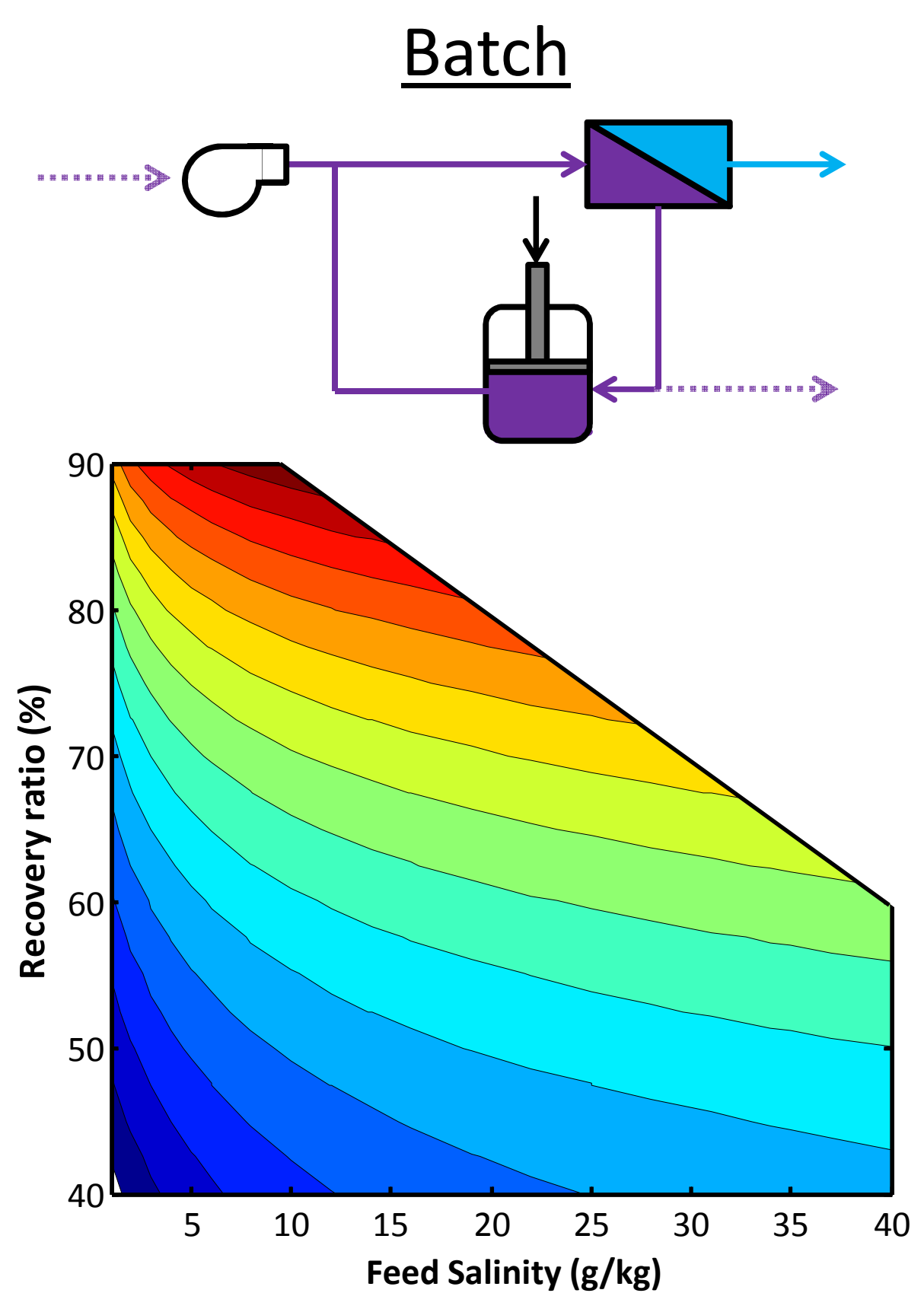